\title{
Economic Brief
}

April 2020, EB20-05

\section{Loan-Delinquency Projections for COVID-19}

\author{
By Grey Gordon, John Bailey Jones, and Jessie Romero
}

\section{The authors forecast the effects of COVID-19 on loan-delinquency rates} under three scenarios for unemployment and house-price movements. Absent policy interventions, the model predicts peak loan-delinquency rates of 2.8 percent in the favorable scenario, $\mathbf{8 . 1}$ percent in the severe scenario, and 3.9 percent in the baseline scenario. The greatest reductions in delinquency are achieved through home mortgage forbearance and student loan forbearance, with fiscal transfers playing a smaller role.

A key concern facing fiscal and monetary policymakers is the extent to which the sharp decline in economic activity stemming from the coronavirus pandemic will affect consumer debt payments. In a recent working paper, two authors of this Economic Brief (Gordon and Jones) used data from the 2016 Survey of Consumer Finances (SCF) to project the incidence of loan delinquency or default in the near future. ${ }^{1}$

To make these projections, Gordon and Jones assumed that delinquency or default occurs when either of two financial ratios - the debt serviceto-income (DSY) ratio and the loan-to-value (LTV) ratio - exceeds certain thresholds. They determined these thresholds by matching 2019 delinquency rates on home mortgage, credit card, and student loan debt and then simulated forward the DSY and LTV ratios for each SCF household under different unemployment and house-price scenarios. Using this methodology, they also assessed how well various policy proposals fiscal transfers, student loan forbearance, and home mortgage forbearance - would mitigate increases in delinquency and default (D-D). While these calculations are not a perfect substitute for a complete economic model, they should provide reasonable first-pass estimates.

The authors considered three scenarios for the unemployment and house-price shocks: a favorable case, a severe case, and an intermediate case (the baseline). ${ }^{2}$ In the absence of policy interventions, they found that:

1. When both shocks follow their baseline trajectories, the D-D rate (measured as the fraction of debt that is ninety-plus days delinquent) rises from 2.3 percent in 2019 to 3.1 percent in 2021 and peaks at 3.9 percent in 2025. The delayed peak is due to persistence in house-price decline. Total write-offs end up being $\$ 580$ billion.

2. When both shocks follow their most favorable trajectories, the D-D rate rises to 2.6 percent in 2021 and peaks at 2.8 percent in 2022. Total write-offs end up being $\$ 420$ billion.

3. When both shocks follow their worst-case trajectories, the D-D rate rises to 3.5 percent in 2021 and peaks at 8.1 percent in late 2025. Total write-offs end up being $\$ 1.1$ trillion. 
Figure 1: Loan-Delinquency Rates with Different Policies (Baseline Scenario)

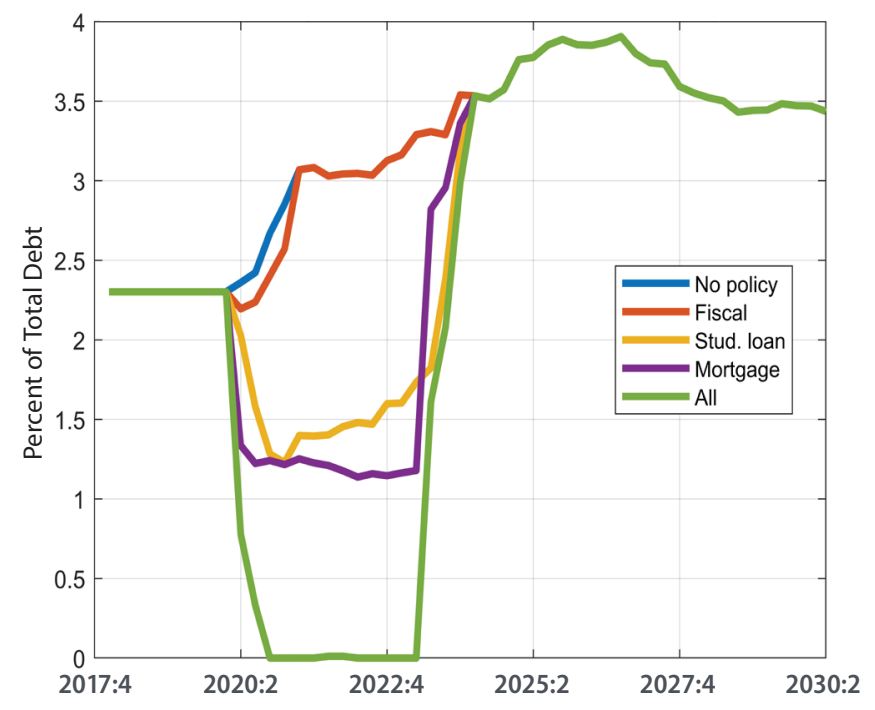

Source: Grey Gordon and John Bailey Jones, "Loan Delinquency Projections for COVID-19," Federal Reserve Bank of Richmond Working Paper No. 20-02, April 15, 2020.

The three policy interventions the authors analyzed begin in the second quarter of 2020 and last for at most three years. Among the three policies they consider, the greatest reduction in the $D-D$ rate is achieved by home mortgage forbearance, then by student loan forbearance, and lastly by fiscal transfers. With all three policies in place, like they currently are under the Coronavirus Aid, Relief, and Economic Security (CARES) act, D-D rates and write-offs fall below their 2019 levels in the near term.

\section{Delinquency Projections with Policy Outcomes}

In the baseline scenario, both unemployment and housing prices follow their baseline (intermediate) trajectories. In particular, the unemployment rate jumps to 20 percent in the second quarter of 2020, stays there for a year, and then returns gradually to its preshock level. House prices fall steadily until the fourth quarter of 2025, with a total decline of 15 percent, and then start to recover. In the absence of any countervailing policies, these shocks lead the D-D rate to peak at about 3.9 percent at the end of 2025, while write-offs reach $\$ 580$ billion. The peak in delinquency coincides with, and is primarily attributable to, the trough in house prices. Even though house prices have the larger effect on peak delinquency rates, in the nearer term, unemployment also raises delinquency through its effects on credit card and student loan debt. But because home mortgage debt ( $\$ 9.56$ trillion in the fourth quarter of 2019 ) is about four times larger than the sum of credit card and student loan debt (\$2.44 trillion), the overall delinquency rate most closely tracks the delinquency rate for home mortgage debt. ${ }^{3}$

Figure 1 shows the effects of the policy interventions in the baseline scenario. Because the policies the authors evaluate all stop before 2025, the peak D-D rates are invariant to policy. However, in the nearer term, the policies lead to significantly lower delinquency rates. Mortgage forbearance generates the largest decreases, but student loan forbearance has significant effects as well. Both of these interventions push delinquency below its baseline rate because they cover households that would have been delinquent even in the absence of coronavirus-related shocks. The effects of the fiscal stimulus are considerably smaller.

It is worth noting that in the absence of a complete model, the authors cannot estimate the true costs and benefits of these interventions. To give just one example, policies that offset income losses or

Figure 2: Loan-Delinquency Rates with Different Policies (Favorable Scenario)

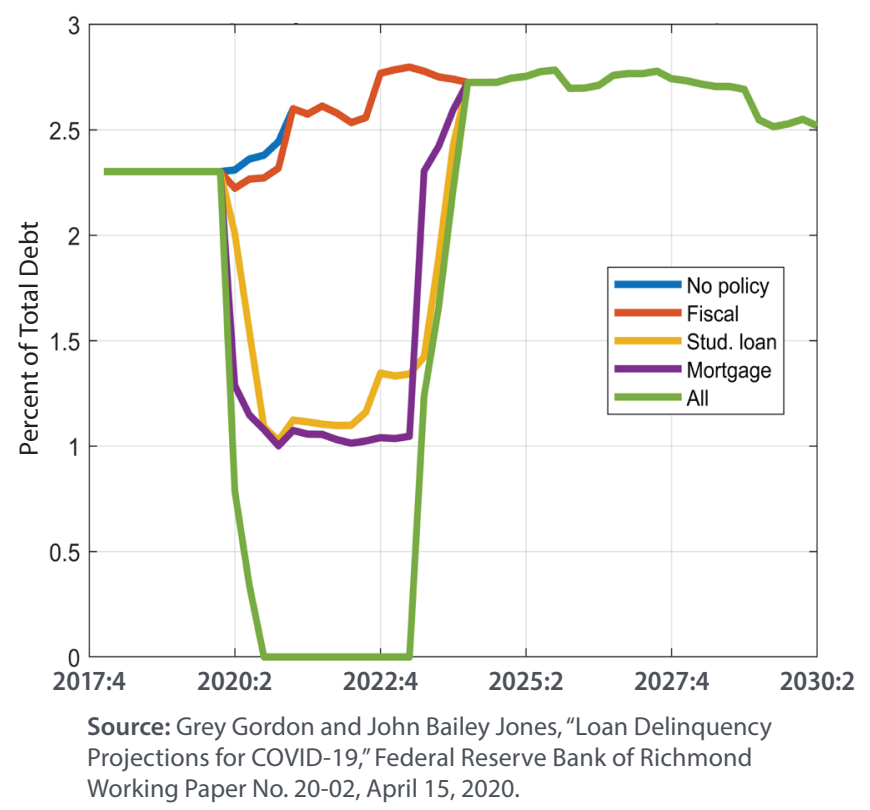


Figure 3: Loan-Delinquency Rates with Different Policies (Severe Scenario)

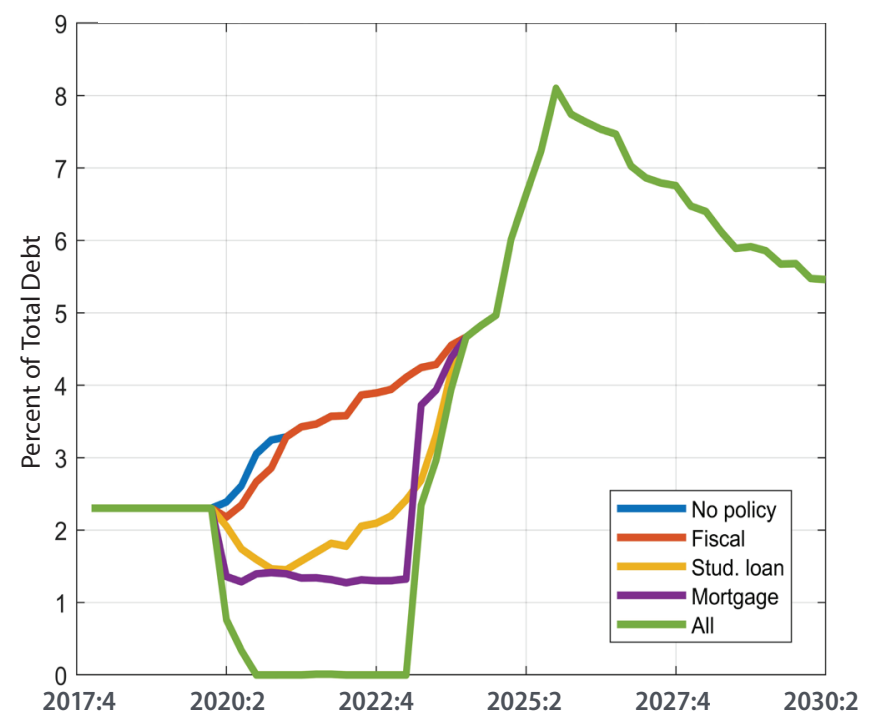

Source: Grey Gordon and John Bailey Jones, "Loan Delinquency Projections for COVID-19," Federal Reserve Bank of Richmond Working Paper No. 20-02, April 15, 2020.

reduce delinquency may also dampen the fall in house prices.

Gordon and Jones also assess a favorable scenario and a severe scenario. In the favorable scenario, delinquency rates remain below 3 percent and writeoffs reach a maximum of $\$ 420$ billion. (See Figure 2 on the previous page.) In the severe scenario, delinquency rates climb to 8.1 percent and write-offs reach more than $\$ 1$ trillion. (See Figure 3.)

It is worth noting that in every scenario, when all three policies are enacted - like they now have been - write-offs drop to essentially zero in 2021. This suggests that delinquency rates will not rise substantially in the near term despite the large disruptions the economy is experiencing.

\section{Model Validation}

A natural question is how well Gordon and Jones's methodology would have predicted the outcomes observed in the Great Recession, when unemployment rose to 10 percent and house prices fell by 25 percent. To assess this in a simple way, the authors assumed unemployment follows its favorable scenario (which features peak unemployment of
10 percent) and house prices follow their severe scenario (which features a decline of 25 percent).

Overall, the D-D rates in the data and in the model show similar increases and similar overall patterns. (See Figure 4 below.) The D-D rate rises sooner in the model than in the data. This is because in the data, the unemployment peak and the house-price trough were only two years apart, whereas in the model, Gordon and Jones assumed that unemployment peaks immediately while house prices bottom out five years later. This is a reasonable assumption given the swift onset of the coronavirus shock, as opposed to the somewhat slower progression of the Great Recession. Taking these considerations into account, the model performs very well.

\section{Conclusion}

Gordon and Jones considered three scenarios for the unemployment and house-price shocks: a baseline case, a favorable case, and a severe case. ${ }^{4}$ In the absence of policy interventions, they found that delinquency rates peak at 2.8 percent to 8.1 percent and write-offs total $\$ 420$ billion to $\$ 1.1$ trillion depending on the scenario. However, in the nearer term, policy leads to significantly lower delinquency rates. Mortgage forbearance generates the largest decreases,

Figure 4: Comparing Great Recession Data to the Model

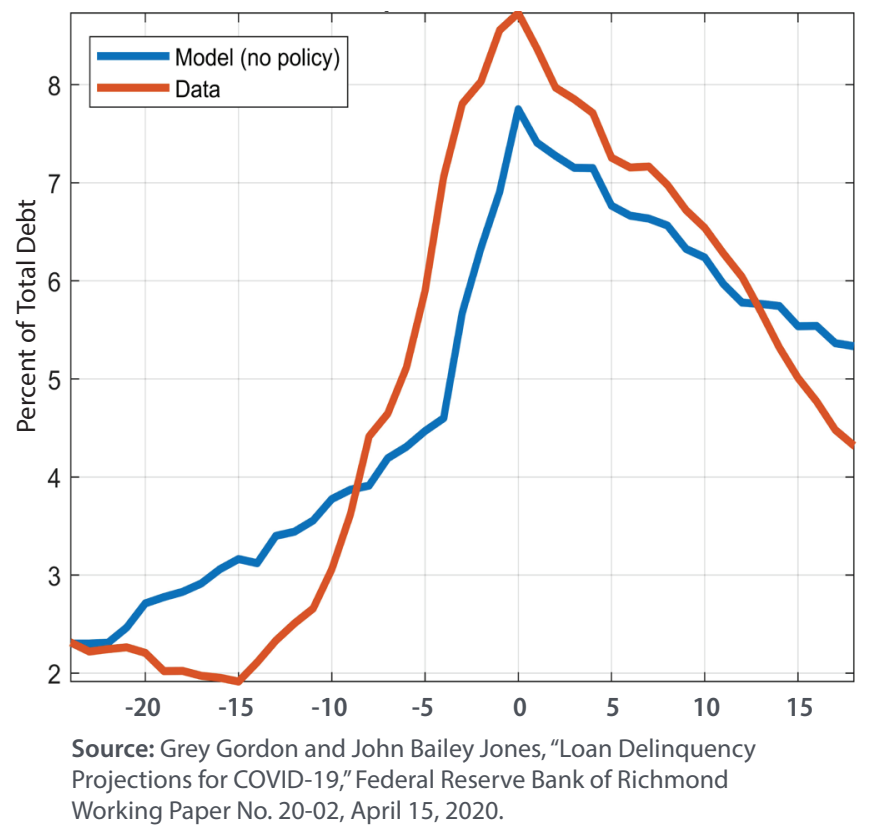


but student loan forbearance has significant effects as well. The effects of the fiscal transfers are considerably smaller. In all three scenarios, when all three policies are enacted - like they now have been write-offs drop to essentially zero in 2021.

Grey Gordon is a senior economist, John Bailey Jones is a senior economist and policy advisor, and Jessie Romero is director of research publications in the Research Department at the Federal Reserve Bank of Richmond.

\section{Endnotes}

${ }^{1}$ Families were included in the sample if their incomes were at least $\$ 10,000$ and their debts (credit card, student loans, home mortgages) totaled at least $\$ 1,000$. Households older than sixty-five were dropped because they do not have much debt and are unlikely to be affected by changes in the aggregate unemployment rates. With these restrictions, the initial sample of 31,240 families dropped to 15,009 . The Survey of Consumer Finances is available online.

2 For details on each scenario, see Grey Gordon and John Bailey Jones, "Loan Delinquency Projections for COVID-19," Federal Reserve Bank of Richmond Working Paper No. 20-02, April 15, 2020

${ }^{3}$ In the absence of loan forbearance, interest rates were held fixed throughout the authors' projections. They therefore do not account for the possibility that interest rates will rise as the economy recovers from the pandemic. Most home mortgages and student loans are fixed-rate, implying that changes in interest rates only affect new borrowers. Gordon and Jones explored the consequences of raising the nominal credit card rate by 3 percentage points annually at different dates. Because credit card debt is a small component of total debt, they found extremely limited effects.

${ }^{4}$ For details on each scenario, see Gordon and Jones, 2020.

This article may be photocopied or reprinted in its entirety. Please credit the authors, source, and the Federal Reserve Bank of Richmond and include the italicized statement below.
Views expressed in this article are those of the authors and not necessarily those of the Federal Reserve Bank of Richmond or the Federal Reserve System. 